\title{
Firms' Private Action Towards Environmental Quality: Where Does Regulation Stand for Non-Adopters of Environment Management Practices?
}

\author{
U.K. Jayasinghe-Mudalige and M. Udugama *
}

\begin{abstract}
This study examines the effects of regulatory framework and legal system on the private action towards environmental quality among food processing firms in Sri Lanka. An Environment Regulation Responsiveness Index, reflecting compliance to solid waste management practices, was used as the measure of firms perception on environment regulation. The results highlight that compliance by the majority of firms was relatively low, especially among the small scale firms, suggesting that the decision maker on environment quality did not consider government regulation as an impotant factor to act on the environment. This calls for a critical revision and adjustments to the policy on environmental quality management both at the national and provincial level in order to promote voluntary action by firms.
\end{abstract}

\section{Background and Motivation}

The inability of social systems comprised of both markets and governments, to provide efficient remedies for economic hazards underscores the importance of collaborative action between the two parties for achieving favorable "second best" solutions. The economic problem of whether a firm can be considered as a "black box" that translates regulatory inputs into compliance outputs in a straightforward manner was, therefore, in the minds of the economists for a longer time (Henson and Heasman, 1998) as it is assumed implicitly that the internal systems within firms can easily generate the desired changes to achieve compliance; so, the non-compliance is a "rogue" outcome. When faced with a new regulation, according to Henson and Heasman (1998), firm's compliance decision does not involve a simple question as to whether comply or not, because it is closely related to decisions regarding 'how to comply', since a continuum of responses is available with it, ranging from 'full compliance' to 'non-compliance'.

\footnotetext{
* Authors are, respectively, Professor and Lecturer, Department of Agribusiness Management, Faculty of Agriculture and Plantation Management, Wayamba University of Sri Lanka, Sri Lanka.
} 
There are claims despite the absence of legally binding regulations, limited institutional capacity and inadequate information hampering formal regulation, firms in many developing countries, in practice, are "fast adopters" of industrial pollution control standards. On the other hand, the high rate of non-compliance" with existing regulatory requirements illustrates that direct government intervention may not be able to fully internalize market failures and can also be subject to policy failures (Pargal and Wheeler, 1996; Hettige et al., 1996). Regulation has, thus, become a major element of the environment in which firms operate that can constraint the strategic behavior of firms (Porter and van Linde, 1995) and food industry is one example of this. In regulating businesses by way of public legislation, according to Stigler (1971), governments force them to operate within certain constraints when the social costs of private market activity are considered high and government action is needed to mitigate a market defect. Capture theory suggests that firms may attempt to co-opt the regulatory process in an attempt to gain strategic advantage and this can occur at the level of the individual firm or the industry through, for example, interest groups (Peltzman, 1976).

The interrelationship between the regulatory activities of government and the strategic behavior of firms is well recognized in the environmental and food economics literature though the vast majority of previous analyses on which were focused on the workings of food markets in the developed countries Marcus (1984), for example, reports three main strategic choices faced by a firm in its response to environmental regulation, including: (a) stonewalling - where the firm attempts to ignore or ride out the problems created by the regulation; (b) opportunity seeking - where the firm sees the regulation as an opportunity to gain competitive or other advantages, and (c) a mixed strategy - where new product development and heavy marketing might characterize firm's response to regulation. Porter and van Linde (1995) argue that firms who adapt quickly to new, more stringent regulations gain a type of 'first mover' advantage in the market place, which leaves them better able to compete, particularly when these regulations become more widely adopted.

However, cooperate response of firms with regard to compliance to regulation may depend on the expected economic benefits in terms of improvements in industrial performance (i.e. market share and profitability) or by sanctions associated with non-compliance (Rugman and Verbeke, 1998). In the case of former, firms may choose to comply voluntarily, whilst in the latter case compliance depends on the strength of enforcement authorities. Nehrt (1998) emphasizes that firms could benefit strategically from regulation in view of the fact that costs of compliance differ according to efficiency in compliance, which, in turn related to factors such as type and size of the firm as it creates opportunities for large firms, in general, to obtain first-mover 
advantage, to enhance competitiveness relative to other firms in the market, and to erect barriers to entry or mobility.

In light of the above, whether a firm takes private actions to augment environment quality, which is more often than not showing characteristics of a public good, in a situation where it can compensate the less significant losses in the market with relatively higher gains obtained through failures in government policy is examined in this study using an empirical approach. We use the special case of Sri Lankan food processing firms' non-compliance to the recently introduced National Strategy for Solid Waste Management of the Ministry of Environment, for this analysis, where the Ministry recommends 9 different solid waste management practices (SWMPs) for a food firm to adopt by taking into account of various production and processing activities it undertakes.

\section{Methodology}

\section{Study Area and the Data}

The primary data, included in the database of the research project funded by the South Asian Network for Development and Environmental Economics (SANDEE) ${ }^{1}$, were used to carry out this analysis. Out of 325 firms in the database, we have selected 160 agri-food processing firms in the Central, North-Western, Southern and Western provinces, which did not have even the "most economical" practices out of the 9 SWMPs recommended by the Ministry in place, i.e.: (a) sorting of waste based on 3R system; (b) composting and (c) good manufacturing practices (GMP). The data were collected from the owner or the top most executive responsible for the firm's decision on environmental aspects between May and June 2010 by means of a series of face-to-face interviews supported by a structured questionnaire and a site inspection (Jayasinghe-Mudalige and Udugama, 2010). The firms included in the sample covered five product categories: (a) coconut products (COP); (b) essential oils (ESO); (c) non-alcoholic beverages (NAB); (d) other processed products (OPP), and (e) processed fruit and vegetables (PFV) and were also categorized as "Large" firms (LRG) and "Small" firms (SML) based on the annual returns. The sample consists of $98(61 \%)$ and $62(39 \%)$ of Small and Large scale firms and 20 (13\%), 44 (28\%), 25 (16\%), 47 (29\%) and 24 (15\%) of COP, ESO, NAB, OPP and PFV firms, respectively.

1 SANDEE research grant SANDEE/Jan08/002 (Corresponding Author is the Principal Investigator). 


\section{Development of an Index to Reflect Firm's Perception on Regulation}

As an initial step towards assessing the managerial perceptions on environmental regulation, a series of attitudinal statements $(n=14)$ included in the questionnaire to reflect different facets of environmental regulations i.e., the existing and anticipated regulatory frameworks and the workings of the legal/judiciary system of the country to protect the environment (Table 1) were used to derive an index - herein referred to as "Environment Regulation Responsiveness Index" (ERRI). The value of ERRI signals the extent to which a manager of a non-compliance firm (i.e. that did not adopt even a single practice out of 9 recommended) perceived various aspects pertaining to the firm's response to regulation. The managers scored on each statement on a two-directional [i.e. yes $(+)$; no (-)] five-point likert-scale, so that range of scoring was -5 to +5 .

Table 1: Attitudinal statements reflecting regulation and the outcome of PCA

\begin{tabular}{clccc}
\hline \multirow{2}{*}{ Attitudinal Statements } & \multicolumn{2}{c}{ VRFL } & \multirow{2}{*}{ Com } \\
\cline { 2 - 3 } & \multicolumn{2}{c}{ F1 } & F2 & \\
\hline $\mathrm{R}_{1}$ & $\begin{array}{l}\text { We always strive to adopt strictly the latest } \\
\text { government regulation in this respect, because there } \\
\text { is no other way to get away from those supervisors }\end{array}$ & $\mathbf{0 . 6 2 9}$ & 0.347 & $\mathbf{0 . 4 1 2}$ \\
\hline $\mathrm{R}_{2}$ & $\begin{array}{l}\text { Currently, we don't have any pressure from Ministry } \\
\text { or any government agency to do that and this; so, I } \\
\text { don't care about these controls }\end{array}$ & 0.161 & $\mathbf{0 . 6 8 9}$ & $\mathbf{0 . 4 1 0}$ \\
\hline $\mathrm{R}_{3}$ & $\begin{array}{l}\text { The "Pradeshiya Sabha, Provincial Government or } \\
\text { Ministry can close my plant, if I am not in } \\
\text { compliance with their requirements }\end{array}$ & -0.077 & $\mathbf{0 . 6 7 7}$ & $\mathbf{0 . 4 6 9}$ \\
\hline $\mathrm{R}_{4}$ & $\begin{array}{l}\text { I am not much concerned about meeting those } \\
\text { recommended controls to manage solid waste of my } \\
\text { firm; I am doing what I can, and what I want }\end{array}$ & $\mathbf{0 . 6 2 3}$ & 0.219 & $\mathbf{0 . 5 6 2}$ \\
\hline $\mathrm{R}_{5}$ & $\begin{array}{l}\text { Nobody knows what regulations that governs this } \\
\text { industry; it is neither written properly nor enforced } \\
\text { adequately }\end{array}$ & $\mathbf{0 . 6 0 3}$ & 0.450 & $\mathbf{0 . 3 9 0}$ \\
\hline $\mathrm{R}_{6}$ & $\begin{array}{l}\text { The "Pradeshiya Shaba's", Provincial and National } \\
\text { governments always modify the environmental } \\
\text { controls they require us to implement; so, we must } \\
\text { keep ahead }\end{array}$ & $\mathbf{0 . 5 4 1}$ & 0.255 & $\mathbf{0 . 4 8 5}$ \\
\hline $\mathrm{R}_{7}$ & $\begin{array}{l}\text { We have to base our waste control measures on what } \\
\text { the government will require tomorrow rather than } \\
\text { today }\end{array}$ & $\mathbf{0 . 5 8 3}$ & 0.164 & $\mathbf{0 . 5 4 2}$ \\
\hline $\mathrm{R}_{8}$ & $\begin{array}{l}\text { I don't think that government would take any further } \\
\text { initiative to mandate advanced systems like ISO } \\
\text { 14000 to overcome this issue, So, I am not worried }\end{array}$ & $\mathbf{0 . 6 4 7}$ & 0.235 & $\mathbf{0 . 3 8 6}$ \\
\hline & & & & \\
\hline
\end{tabular}


Table 1 contd...Attitudinal statements reflecting regulation and the outcome of PCA

Attitudinal Statements

VRFL Com

$\mathrm{R}_{9} \quad$ Around the globe, there are many changes to

\begin{tabular}{ccc}
\multicolumn{2}{c}{ VRFL } & \multirow{2}{*}{ Com } \\
\cline { 1 - 2 } F1 & F2 & \\
\hline $\mathbf{0 . 0 7 4}$ & 0.149 & $\mathbf{0 . 4 2 4}$
\end{tabular}
environmental policy; these things will come to us in the near future; Hence, why don't we ready ourselves to face that challenge.

\begin{tabular}{llllc}
\hline $\mathrm{R}_{10}$ & $\begin{array}{l}\text { If you do not have a sound waste management } \\
\text { system in place you face a lot of risk that someone } \\
\text { will sue you }\end{array}$ & $\mathbf{0 . 8 6 0}$ & -0.277 & $\mathbf{0 . 1 8 1}$ \\
\hline $\mathrm{R}_{11}$ & $\begin{array}{l}\text { I never heard that owner of a firm of my type put into } \\
\text { jail for his misconduct on environment; so, why do I } \\
\text { fear without reason. }\end{array}$ & $\mathbf{0 . 5 6 9}$ & -0.306 & $\mathbf{0 . 5 2 8}$ \\
\hline $\mathrm{R}_{12}$ & $\begin{array}{l}\text { The "fines" and "compensations" imposed by } \\
\text { judiciary is marginal; better you work on your agenda } \\
\text { without caring to such penalties. }\end{array}$ & 0.343 & $\mathbf{- 0 . 5 4 2}$ & $\mathbf{0 . 5 5 5}$ \\
\hline $\mathrm{R}_{13}$ & $\begin{array}{l}\text { Better environmental controls in the firm prevent } \\
\text { anybody taking me to courts alleging that I pollute } \\
\text { their neighborhood }\end{array}$ & $\mathbf{0 . 8 7 2}$ & -0.232 & $\mathbf{0 . 1 7 8}$ \\
\hline $\mathrm{R}_{14}$ & $\begin{array}{l}\text { The time and money that I will have to spend on } \\
\text { judicial matters far exceed that I will have to spend on } \\
\text { adopting these controls; so I adopt them }\end{array}$ & $\mathbf{0 . 7 1 6}$ & -0.390 & $\mathbf{0 . 3 3 2}$ \\
\end{tabular}

Note: VRFL - Varimax Rotated Factor Loadings; AS - Attitudinal Statement; COM

- Communalities

\section{Confirmatory Factor Analysis}

Perception being a directly unobservable phenomenon, the scores provided by respondents were scrutinized with the help of the Statistical Package for Social Sciences (SPSS) [version 14] to overcome empirical issues of non-exclusivity, endogeneity, subjectivity, unobservability by applying a number of statistical tests specified under the Confirmatory Factor Analysis, including: (a) Construct/Scale Reliability - measures whether a set of statements are consistent in their measurement and is customary to use the Cronbach's alpha for this purpose and (b) Unidimensionality - evaluated by examining the loading of statements on to one factor (Hair et al., 2006).

The Confirmatory Factor Analysis (CFA), which is an interdependence technique stated under the Multivariate Data Analysis techniques, that is used commonly to define the underlying structure among a set of variables of an analysis objectively, was employed to test this condition. The CFA techniques helps particularly to find a way to condense the information contained in these 14 statements (i.e. original variables) into a smaller set of new composite dimensions or variates with a minimum loss of 
information by taking into account of the total variance amongst the original variables (De Vellis, 1991).

In principle, the ERRI was specified to meet the characteristics of a Weighted Additive Index (Powers and Xie, 1999) in the form of: $E R R I_{i}=\sum_{i=1}^{n} W_{s}\left[a\left(R_{s}\right)_{i}\right] /\left[a\left(R_{s}\right)\right]$, where, the term $\mathrm{a}\left(\mathrm{R}_{s}\right)_{i}$ denotes the score given by a respondent $(i)$ to a statement $\left(\mathrm{R}_{\mathrm{s}}\right)$ [s = number of statements] on the likert-scale. To derive ERRI for a given firm, the summation of scores of all the statements $(s=14)$ was divided by the Maximum Potential Score $\left[a\left(R_{s}\right)\right]$ to normalize the value of the index. For this particular analysis, the value of [a $\left(\mathrm{R}_{\mathrm{s}}\right)$ ] was 70 (i.e. maximum score of +5 on the likert-scale $\mathrm{x} 14$ statements]. With the normalization, the values of ERRI for a given firm, thus, ranges from -1 to 1 , where -1 reflects the "perfect perceptions of the decision maker towards compliance to regulation", and 1 on the other extreme reflects his/her "perfect perceptions towards non-compliance to regulation".

This empirical analysis aims capture the extent to which the managers perceived the effect of each attitudinal statement on their decision to adopt SWMPs in the firm. Logically, even under the circumstances where the 14 attitudinal statements stated originally were confined to a single variate (i.e. unidimensionality), all the respondents in the sample may not value the underlying phenomenon explained in a given statement as equally important for them to act towards environmental quality. If so, it is imperative to incorporate this variation into the analysis. To fulfill this condition, we have weighted the index using appropriate weights (W) taken from the results of the Factor Analysis, i.e. all things equal to ERRI expressed earlier, the term W in above equation represents the weight assigned to each statement to characterize the variation of responses of respondents.

\section{Results and Discussion}

\section{Outcome of the Confirmatory Factor Analysis}

While there is no rigorous criterion specified to assess when factor loadings are significant, Spector (1992) suggests that a minimum value of around $0.30-0.35$ indicates that the indicators loads onto a factor, thus unidimensionality condition is satisfied. The outcome of CFA carried out using the scores provided by 160 respondents to 14 statements on the fivepoint multidirectional likert-scale (i.e. -5 to +5 ) helped to extract two different factors (see, Table 1). This highlights that the scores provided by respondents to these statements were multidimensional. 


\section{Derivation of ERRI}

Given the multidimensional nature of statements, the scores given to the statements loaded into a given factor (e.g. statements $\mathrm{R}_{1}, \mathrm{R}_{4}, \mathrm{R}_{5}, \mathrm{R}_{6}, \mathrm{R}_{7}$, $R_{8}, R_{9}, R_{10}, R_{11}, R_{13}$ and $R_{14}$ for the Factor $1 ; R_{2}, R_{3}$ and $R_{12}$ for the Factor 2) were taken separately to obtain the relative weight of the respective factor so that the value of ERRI would truly reflect the varying levels of perceptions the respondents in the sample possess for statements written on various issues pertaining to environmental regulation. Figure 1 shows that Mean value of scores obtained by each statement.

Figure 1: $\quad$ Mean values of the attitudinal statements

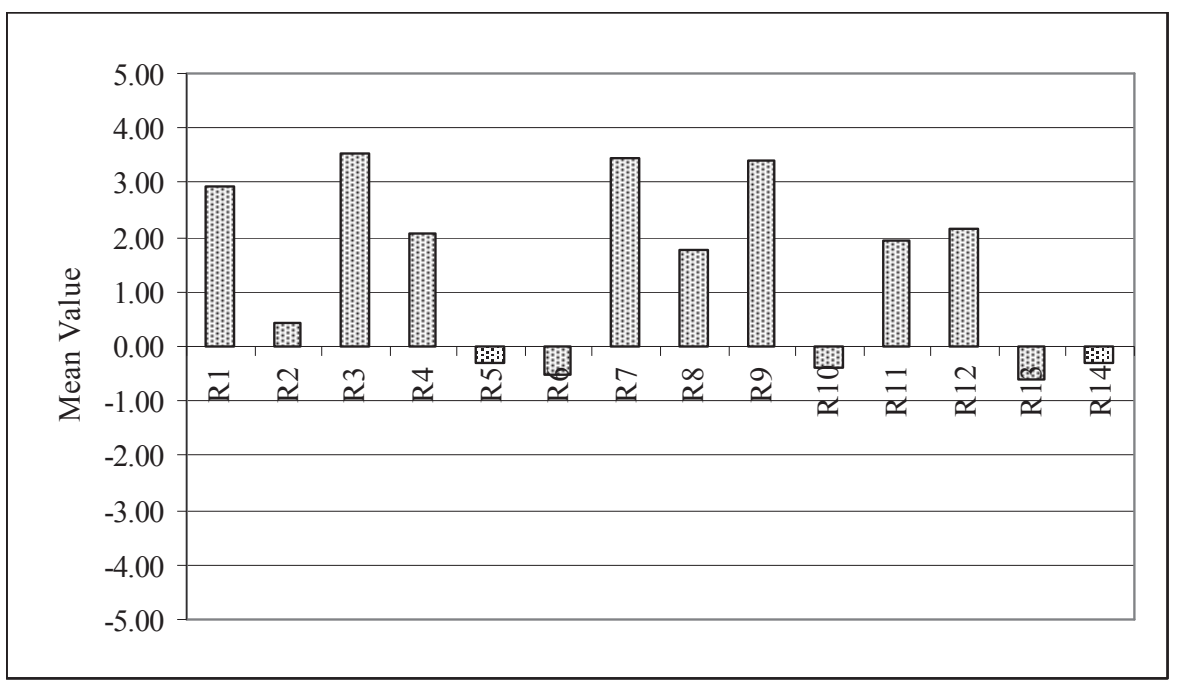

The lowest value was given to $R_{13}$ (Better environmental controls in the firm prevent anybody taking me to courts alleging that I pollute their neighborhood) implies that the inefficiencies in penalties (i.e. fines and compensations) and lack of community awareness of regulations are major determinants affecting non adoption of these controls. The response by firms of different size to certain statements varied significantly, for example, the difference of ERRI between large to small was very high with regard to the statement $\mathrm{R}_{10}$ : "If you do not have a sound waste management system in place you face a lot of risk that someone will sue you" highlighting the impact of liability laws on different firm sizes.

The responsiveness to the regulations varied significantly with the firm type within a low range. Among the different types, the Coconut sector had a relatively higher responsiveness while for other types of firms the affinity varied significantly i.e. for the statement $\mathrm{R}_{5}$ : "Nobody knows what 
regulations governs this industry; it is neither written properly nor enforced adequately" the responses varied drastically implying the lack of awareness and interest on regulation information irrespective of the firm type.

The outcome of analysis shows that the magnitude of ERRI of a majority of the firms was relatively low (i.e. in between 0 to 0.4 ). This is pretty much clear in the context of firm size, where the value of which of the small scale firms were relatively low indicating that these firms' did not consider the government regulation as an important factor governing their action on environment (Figure 2).

Figure 2: $\quad$ Mean values of ERRI for different sub samples

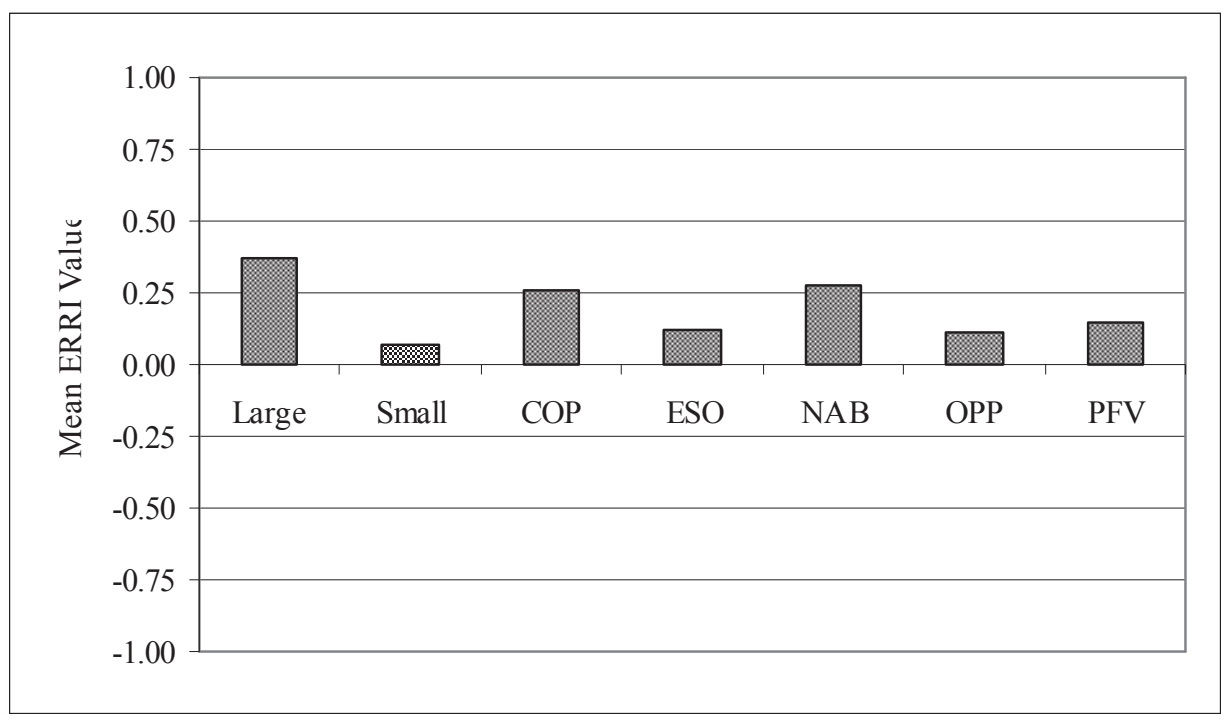

However, the large firms, though with relatively low values, showed a positive response towards environmental regulations due to many reasons such the likelihood to undertake actions to reduce their environmental impacts if made mandatory by the regulatory framework. The majority of the small firms showed relatively low responsiveness towards regulations other than for the statements reflecting existing government regulations. Though not adopted, large firms showed higher positive values for statements reflecting anticipated regulations implying the fact there is potential for the adoption of recommended practices in the future.

The results clearly show that majority of the firm irrespective of the plant level characteristics, do not perceive the regulatory framework to have a considerable impact on their adoption of solid waste management practices proving the typical developing country conditions. However, they do have an 
affinity towards adoption of these due to other market-based incentives such as reputation, sales etc. Also the fact that they perceive the anticipated government regulation relatively more important also highlights possible adoption in the future. Nevertheless, according to the decision makers, among many limitations affecting the adoption of these practices, the lack of financial assistance, limited space availability for construction of some methods and the asymmetric information from specially the governing bodies rank high among the constraining factors.

\section{Conclusions}

The results on the role of regulatory incentives in influencing adoption of SWMPs suggests that firms do not consider the regulatory framework of the government a promising factor governing their actions on environment. Especially, the current regulations do not seem to motivate adoption thus, and the current government information provision, monitoring and regulatory roles do not matter very much yet. Firms do tend to adopt practices when they anticipate that there may be stricter regulations in the future. Thus, the idea of stricter regulations seems to matter but current regulations seem to be too weak to make a difference. However, legal liability does influence a higher degree of adoption. The outcome also highlights that a vast majority ( $>90 \%$ ) of firms have "no plans" to adopt any of these practices in the near future citing the financial burden and the lack of information on SWMPs. Further, it could be concluded that the firms in the agri-food processing industry show low levels of responsiveness to regulations irrespective of the firm size/type which may have caused the nonadoption of SWMPs. Further, the firm's decision to "not adopt" these practices even after three years time of introducing the regulation highlights the lack of strength of the regulatory framework in stimulating adoption.

From an economic perspective, regulators would aim to maximize welfare when enforcing a regulation. However, many plants avoid complying with environmental regulations because monitoring and enforcement are infrequent. Indeed, the outcome of the analysis implies that conventional policy discussion on environmental quality management at the level of firm has been too narrow, focusing only on the recommendations but not on proper implementation aiming environmental performance. In Sri Lanka, regulations may need to be altered at the provincial government level to overcome current shortcomings in the regulatory system. It is also possible that the situation would improve if firms were more carefully consulted during the process of establishing regulations and setting standards. The outcome of the analysis, thus, calls attention for a critical revision and adjustments to the policy on environmental quality management at the National and Provincial level in order to promote voluntary action by firms. 


\section{Acknowledgements}

Authors wish to express their gratitude to the South Asian Network for Development and Environmental Economics (SANDEE) for providing financial assistance for carrying out this research study and to the managers/owners of agri-food processing firms who participated in the process of data collection.

\section{References}

De Vellis, R.F. (1991). Scale Development: Theory and Application. Newbury Park: Sage Publications.

Hair, J.F., R.E. Anderson, R.L. Tatham and W.C. Black (2006). Multivariate Data Analysis with Readings. Englewood Cliffs, New Jersey: Prentice Hall.

Henson, S. and M. Heasman (1998). Food Safety Regulation and the Firm: Understanding the Process of Compliance. Food Policy, 23(1):9-23.

Hettige, H., M. Huq, S. Pargal and D. Wheeler (1996). Determinants of Pollution Abatement in Developing Countries: Evidence from South and Southeast Asia. World Development, 24:1891-1904.

Jayasinghe-Mudalige, U.K. and J.M.M. Udugama (2010). Motives for Firmst Adopt Solid Waste Management Controls: The Case of Food Processing Sector in Sri Lanka. Working Paper, South Asian Network for Development and Environmental Economics (SANDEE), ICIMOD Nepal.

Marcus, A.E. (1984). The Adversary Economy. London: Quorum Books.

Nehrt, C. (1998). Maintainability of First Mover Advantages When Environmental Regulations Differ Between Countries. Academy of Management Review, 23(1):77-97.

Pargal, S. and D. Wheeler (1996). Informal Regulation of Industrial Pollution in Developing Countries: Evidence from Indonesia. Journal of Political Economy, 104(6):1314-27.

Peltzman, S. (1976). Towards a More General Theory of Regulation. Journal of Law and Economics, 19:211-240. 
37

Porter, M.E. and C. Van der Linde (1995). Towards a New Conception of the Environment-Competitiveness Relationship. Journal of Economic Perspectives, 9(4):97-118.

Rugman, A.M. and A. Verbeke (1998). Corporate Strategies in Environmental Regulations. Strategic Management Journal, 19(4):363-375.

Spector, P.E. (1992). Summated Rating Scale Construction. In Basic Management. M.S. Lewis-Beck (ed.), Newbury Park: Sage Publications.

Stigler, G. (1971). The Theory of Economic Regulatio. Bell Journal of Economics and Management Science, 2:3-21. 